\title{
Lisina digestível para suínos machos não castrados de alto potencial genético em fase de crescimento
}

\author{
Digestible lysine for pigs not castrated of high genetic potential in growth phase
}

\author{
Charles Kiefer ${ }^{I}$ Juarez Lopes Donzele ${ }^{I I}$ Rita Flávia Miranda de OliveiraII
}

\section{RESUMO}

Este estudo foi realizado com o objetivo de determinar a exigência de lisina digestível para suínos machos não castrados de alto potencial genético em fase de crescimento. Foram utilizados 320 machos não castrados e 80 castrados, com peso inicial de $27,75 \pm 1,61 \mathrm{~kg}$, distribuídos em delineamento experimental em blocos ao acaso composto por cinco tratamentos $(0,90 ; 1,00 ; 1,10$ e $1,20 \%$ de lisina digestível para não castrados e 1,10\% de lisina digestível para castrados), oito repetições, com 10 animais cada. O aumento da concentração de lisina na dieta aumentou de forma linear $(P<0,05)$ o peso final, consumo de lisina diário, ganho em peso diário e consumo de lisina por quilograma de ganho em peso e reduziu a conversão alimentar dos machos não castrados. Os tratamentos não influenciaram $(P>0,05) o$ consumo de ração diário dos machos não castrados. Suínos castrados apresentaram maior $(P<0,05)$ consumo diário de ração e pior $(P<0,05)$ conversão alimentar em relação aos não castrados alimentados com as dietas contendo 1,00; 1,10 e 1,20\% de lisina. Machos castrados apresentaram consumo de lisina diário superior $(P<0,05)$ aos não castrados alimentados com a dieta contendo 0,90; 1,00 e 1,10\% de lisina. Suínos castrados apresentaram menor $(P<0,05)$ ganho de peso diário e peso final em relação aos não castrados consumindo a dieta contendo 1,20\% de lisina. Foi observado maior $(P<0,05)$ consumo de lisina por quilograma de ganho em peso dos machos castrados em relação aos não castrados. Recomenda-se o mínimo de 1,20\% de lisina digestível na dieta de suínos machos não castrados de alto potencial genético em fase de crescimento.

Palavras-chave: aminoácidos, desempenho, exigência, nutrição, proteína ideal.

\begin{abstract}
This study was conducted to determine the digestible lysine requirement for non castrated pigs of high genetic potential in growth phase. It was used 320 not castrated and 80 castrated males, with initial weight of $27.75 \pm 1.61 \mathrm{~kg}$, distributed in a randomized block design consisting of five treatments $(0.90,1.00,1.10$ and $1.20 \%$ digestible lysine for not castrated and $1.10 \%$ digestible lysine for castrated males), eight replicates with ten animals each. The increase of lysine concentration in the diet increased linearly $(P<0.05)$ the final weight, daily lysine intake, daily weight gain and lysine intake per kilogram of weight gain and reduced feed conversion of not castrated males. The treatments did not affected $(P>0.05)$ daily feed intake of not castrated males. Castrated males had higher $(P<0.05)$ daily feed intake and lower $(P<0.05)$ feed conversion compared to not castrated fed diets containing 1.00, 1.10 and $1.20 \%$ lysine. Castrated males had higher daily lysine intake $(P<0.05)$ than not castrated fed diets containing 0.90 , 1.00 and $1.10 \%$ lysine. Castrated pigs had lower $(P<0.05)$ daily gain and final weight in relation to non castrated consuming a diet containing $1.20 \%$ lysine. Castrated males had higher $(P<0.05)$ lysine intake per kilogram of weight gain compared with not castrated. It is recommended a minimum of $1.20 \%$ lysine in the diet of not castrated male pigs with high genetic potential in growth phase.
\end{abstract}

Key words: amino acids, ideal protein, nutrition, performance, requirement.

\section{INTRODUÇÃO}

Com o advento da imunocastração, método alternativo ao de castração cirúrgica tradicional, a

'Departamento de Zootecnia, Universidade Federal de Mato Grosso do Sul (UFMS), 79074-460, Campo Grande, MS, Brasil. Email: charles@nin.ufms.br. Autor para correspondência.

"Departamento de Zootecnia, Universidade Federal de Viçosa (UFV), Viçosa, MG, Brasil. 
produção de suínos machos não castrados vem crescendo progressivamente no Brasil, fato que está relacionado à superioridade desses animais em relação aos castrados (FÁVERO, 2001).

Diversos estudos compilados em revisão (XUE et al., 1997) têm evidenciado que os suínos machos não castrados apresentam superioridade quanto à eficiência de utilização dos nutrientes para ganho em peso e apresentam menor quantidade de gordura, resultando em maior percentual de carne na carcaça, o que torna a produção desses animais economicamente mais rentável.

O melhor desempenho proporcionado pelo aumento da deposição proteica na carcaça dos machos não castrados é acompanhado do aumento da exigência de aminoácidos na dieta (WILLIAMS et al., 1984). Considerando suínos na mesma faixa de peso corporal, os machos castrados e as fêmeas exigem menores concentrações de lisina na dieta em relação aos machos não castrados (YEN et al., 1986), o que, em situações práticas, impossibilita o fornecimento das mesmas dietas para fêmeas, machos castrados e não castrados.

Contudo, existem poucas informações relacionadas à exigência de lisina para suínos machos não castrados em fase de crescimento. Além disso, considera-se que os níveis de lisina preconizados pela literatura estejam desatualizados, uma vez que os suínos contemporâneos, geneticamente selecionados para maior deposição proteica na carcaça, apresentam maiores exigências de lisina e dos demais aminoácidos para o máximo desempenho (GRANDHI \& NYACHOTI, 2002). Entre os níveis propostos na literatura estão os de 0,86\% de lisina total para suínos dos 25 aos $55 \mathrm{~kg}$ (WILLIAMS et al., 1984); 0,87\% de lisina total dos 25 aos 70kg (CASTAGNA et al., 1999); e 0,89\% de lisina total dos 30 aos 60kg (DONZELE et al., 1994). Por sua vez, as tabelas brasileiras (ROSTAGNO et al., 2005) não apresentam informações quanto à exigência nutricional dos suínos machos não castrados.

Considerando o aumento na criação de machos suínos não castrados destinados à produção de carne, associado à carência de informações sobre as exigências aminoacídicas desses animais, realizouse este estudo com o objetivo de determinar a exigência de lisina digestível para suínos machos não castrados de alto potencial genético em fase de crescimento.

\section{MATERIAL E MÉTODOS}

Foram utilizados 320 suínos machos não castrados e 80 machos castrados, Duroc/Pietran x Large White/Landrace, de alto potencial genético para deposição de proteína na carcaça, dos 67 aos 107 dias e com peso inicial de $27,75 \pm 1,61 \mathrm{~kg}$. Os animais foram alojados em baias equipadas com comedouros automáticos e bebedouros tipo chupeta, localizadas em prédio de alvenaria, coberto com telha de amianto, com piso de concreto e lâmina d’água. Durante o período experimental, as temperaturas foram monitoradas diariamente às $7 \mathrm{~h}, 12 \mathrm{~h}$ e $17 \mathrm{~h}$, por meio de termômetros de bulbo seco e úmido e de globo negro instalados no centro do galpão.

Os animais foram distribuídos em delineamento experimental em blocos ao acaso, com cinco tratamentos (quatro tratamentos constituídos por suínos machos não castrados alimentados com dietas contendo 0,90; 1,00; 1,10 e 1,20\% de lisina digestível, e um tratamento controle constituído por suínos machos castrados alimentados com a dieta contendo $1,10 \%$ de lisina digestível), com oito repetições e 10 animais por repetição. Estabeleceu-se o tratamento com a dieta contendo 1,10\% de lisina digestível para os suínos machos castrados (grupo controle) considerando que esse nível, com as respectivas relações aminoacídicas, superou as exigências nutricionais dessa categoria conforme estabelecido por ROSTAGNO et al. (2005). Levou-se em consideração o peso inicial dos suínos para a formação dos blocos.

As dietas experimentais (Tabela 1) foram formuladas à base de milho e farelo de soja, suplementadas com minerais, vitaminas e aminoácidos. Os aminoácidos sintéticos DL-Metionina, L-Treonina e L-Triptofano foram utilizados para manter as mesmas relações aminoacídicas da proteína ideal das dietas, de acordo com ROSTAGNO et al. (2005), para suínos em crescimento. As dietas e a água foram fornecidas à vontade durante o período experimental. Os desperdícios de ração depositados no chão, na região próxima do comedouro, foram coletados diariamente, pesados e somados às sobras do comedouro ao final do experimento.

Os animais foram pesados no início e no final do experimento para determinação dos consumos diários de ração e de lisina, do ganho diário de peso e da conversão alimentar. A quantidade de lisina digestível por quilograma de ganho em peso foi calculada a partir dos resultados obtidos para ingestão diária de lisina, sendo subtraída pela quantidade de lisina exigida diariamente para a mantença e dividido o resultado pelo ganho em peso diário observado. A exigência diária de lisina para mantença foi calculada segundo a equação: Lisina para mantença (g)=0,036x (peso médio) ${ }^{0,75}$, proposta por FULLER et al. (1989).

As análises estatísticas foram realizadas por meio de programa estatístico (SAS, 2001). Os dados 
Tabela 1 - Composição percentual e nutricional das dietas experimentais.

\begin{tabular}{|c|c|c|c|c|}
\hline \multirow{2}{*}{ Ingredientes (\%) } & \multicolumn{4}{|c|}{-------------------------Níveis de lisina (\%)-------------------------- } \\
\hline & 0,90 & 1,00 & 1,10 & 1,20 \\
\hline Milho grão & 64,287 & 64,287 & 64,287 & 64,287 \\
\hline Farelo de soja $45 \%$ & 30,745 & 30,745 & 30,745 & 30,745 \\
\hline Fosfato bicálcico & 1,207 & 1,207 & 1,207 & 1,207 \\
\hline Banha & 1,425 & 1,425 & 1,425 & 1,425 \\
\hline Caulim & 1,000 & 0,826 & 0,568 & 0,301 \\
\hline Calcário & 0,631 & 0,631 & 0,631 & 0,631 \\
\hline Sal comum & 0,405 & 0,405 & 0,405 & 0,405 \\
\hline Suplemento vitamínico ${ }^{1}$ & 0,150 & 0,150 & 0,150 & 0,150 \\
\hline Suplemento mineral $^{2}$ & 0,150 & 0,150 & 0,150 & 0,150 \\
\hline L-Lisina $\mathrm{HCl}$ 78\% & 0,000 & 0,129 & 0,258 & 0,387 \\
\hline DL-Metionina 99\% & 0,000 & 0,039 & 0,099 & 0,160 \\
\hline L-Treonina 98,5\% & 0,000 & 0,006 & 0,075 & 0,144 \\
\hline L-Triptofano $98 \%$ & 0,000 & 0,000 & 0,000 & 0,008 \\
\hline Total & 100,00 & 100,00 & 100,00 & 100,00 \\
\hline Proteína bruta (\%) & 19,24 & 19,24 & 19,24 & 19,24 \\
\hline Energia metab. $\left(\mathrm{kcal} \mathrm{kg}^{-1}\right)$ & 3.230 & 3.230 & 3.230 & 3.230 \\
\hline Lisina digestível (\%) & 0,900 & 1,000 & 1,100 & 1,200 \\
\hline Triptofano digestível (\%) & 0,208 & 0,208 & 0,208 & 0,216 \\
\hline Treonina digestível (\%) & 0,644 & 0,650 & 0,715 & 0,780 \\
\hline Met + cist digestível (\%) & 0,562 & 0,600 & 0,660 & 0,720 \\
\hline Isoleucina digestível (\%) & 0,739 & 0,739 & 0,739 & 0,739 \\
\hline Valina digestível (\%) & 0,815 & 0,815 & 0,815 & 0,815 \\
\hline Cálcio (\%) & 0,631 & 0,631 & 0,631 & 0,631 \\
\hline Fósforo disponível (\%) & 0,330 & 0,330 & 0,330 & 0,330 \\
\hline Fósforo total (\%) & 0,541 & 0,541 & 0,541 & 0,541 \\
\hline Sódio (\%) & 0,180 & 0,180 & 0,180 & 0,180 \\
\hline
\end{tabular}

${ }^{1}$ Conteúdo por kg de produto: Cobre, 30.000mg; Zinco, 160.000mg; Iodo, 1.900mg; Ferro, 100.000mg; Manganês, 70.000mg; Cobalto, 375mg; Selênio, 150mg; veículo q.s.p.1000g.

${ }^{2}$ Conteúdo por kg de produto: Vitamina A 840.000UI; Vitamina $\mathrm{D}_{3}$, 210.000UI; Vitamina E, 1.522,5mg; Ácido fólico, 63mg; Pantotenato de cálcio, 1.680mg; Biotina, 5,25mg; Niacina, 2.520mg; Piridoxina, 210mg; Riboflavina, 588mg; Tiamina, 210mg; Vitamina $\mathrm{B}_{12}$, 3.150mg; Vitamina $\mathrm{K}_{3}$, 105mg; Selênio, 63mg; Colina, 65.250mg; veículo q.s.p.1000g.

obtidos foram submetidos à análise de variância, e a exigência de lisina digestível para os suínos machos não castrados foi determinada por meio de análises de regressão polinomial. As médias das variáveis obtidas para os suínos machos castrados foram comparadas às dos machos não castrados por meio do teste de Dunnett.

\section{RESULTADOS E DISCUSSÃO}

Durante o período experimental, a temperatura do ar registrada no interior do galpão foi de $26,3 \pm 4,1^{\circ} \mathrm{C}$, a umidade relativa foi de $75,7 \pm 15,3 \%$, a temperatura de globo negro foi de $26,8 \pm 4,3^{\circ} \mathrm{C}$ e o ITGU correspondente foi de 75,6 $\pm 5,1$. Considerando que a temperatura crítica máxima para essa categoria é de $27^{\circ} \mathrm{C}$ (SAMPAIO et al., 2004), pode-se inferir, a partir dos desvios térmicos obtidos, que os animais foram submetidos a períodos de temperaturas ambientais de estresse por calor durante a execução da pesquisa.

Foi constatado efeito $(\mathrm{P}<0,05)$ da concentração de lisina digestível da dieta sobre o ganho em peso diário (GPD) dos suínos machos não castrados (Tabela 2), que aumentou de forma linear de acordo com a equação GPD=527,21+235,02 Lisina digestível, $\mathrm{r}^{2}=0,98$. Variação significativa do ganho de peso em função da concentração de lisina da dieta também foi observado por WILLIAMS et al. (1984) e por DONZELE et al. (1994) em suínos machos não castrados. No entanto, o ganho em peso diário máximo de $813 \mathrm{~g}$, obtido neste estudo, pode ser considerado baixo, principalmente quando comparado aos ganhos de 822 e $840 \mathrm{~g}$ observados, respectivamente, nos estudos realizados pelos respectivos autores com suínos de

Ciência Rural, v.40, n.7, jul, 2010. 
Tabela 2 - Desempenho de suínos machos não castrados em fase de crescimento, em função da concentração de lisina digestível das dietas.

\begin{tabular}{|c|c|c|c|c|c|c|c|c|}
\hline Categoria & Lisina, \% & PI & $\mathrm{PF}^{\mathrm{L}}$ & CRD & $\mathrm{CLD}^{\mathrm{L}}$ & $\mathrm{GPD}^{\mathrm{L}}$ & $\mathrm{L} / \mathrm{GP}^{\mathrm{L}}$ & $\mathrm{CA}^{\mathrm{L}}$ \\
\hline MNC & 0,90 & 27,92 & 57,42 & 1.739 & 15,65 & 741 & 20,33 & 2,35 \\
\hline MNC & 1,00 & 28,07 & 58,39 & 1.662 & 16,62 & 761 & 21,15 & 2,19 \\
\hline MNC & 1,10 & 27,86 & 58,87 & 1.650 & 18,15 & 781 & 22,62 & 2,13 \\
\hline MNC & 1,20 & 27,69 & 60,09 & 1.648 & 19,78 & 813 & 23,59 & 2,03 \\
\hline MC & 1,10 & 27,19 & 56,93 & 1.781 & 19,60 & 748 & 25,61 & 2,40 \\
\hline \multicolumn{9}{|l|}{ Contrastes } \\
\hline MNC x MC & $0,90 \times 1,10$ & ns & ns & ns & $*$ & ns & * & Ns \\
\hline MNC x MC & $1,00 \times 1,10$ & ns & ns & $*$ & $*$ & ns & $*$ & $*$ \\
\hline MNC $\mathrm{x}$ MC & $1,10 \times 1,10$ & ns & ns & $*$ & $*$ & ns & $*$ & $*$ \\
\hline MNC x MC & $1,20 \times 1,10$ & ns & $*$ & $*$ & ns & $*$ & $*$ & $*$ \\
\hline CV (\%) & - & 3,59 & 5,00 & 7,32 & 6,90 & 7,58 & 6,16 & 5,13 \\
\hline
\end{tabular}

MNC (macho não castrado); MC (macho castrado); PI (peso inicial, kg); PF (peso final, kg); CRD (consumo de ração diário, gramas); CLD (consumo de lisina diário, gramas); GPD (ganho de peso diário, gramas); L GP${ }^{-1}$ (lisina por kg de ganho de peso, gramas); CA (conversão alimentar) e CV (coeficiente de variação).

${ }^{\mathrm{L}}$ Efeito linear para suínos machos não castrados $(\mathrm{P}<0,05)$.

* Média dos machos não castrados diferem $(\mathrm{P}<0,05)$ da média dos machos castrados pelo teste de contrastes.

${ }^{\text {ns }}$ Efeito não significativo $(\mathrm{P}>0,05)$ pelo teste de contrastes.

menor potencial genético. Uma provável explicação para o baixo ganho de peso obtido pelos animais deste estudo pode estar relacionada às elevadas temperaturas ambientais registradas durante a execução da pesquisa.

Quando se comparou o ganho em peso diário dos machos não castrados com o dos castrados, verificou-se que somente os animais não castrados consumindo a dieta contendo $1,20 \%$ de lisina digestível apresentaram ganho superior $(\mathrm{P}<0,05)$ aos castrados. $\mathrm{O}$ resultado confirma o maior potencial de ganho em peso dos machos não castrados em relação aos castrados, bem como a maior exigência em aminoácidos para que esse potencial seja atingido (YEN et al., 1986).

O consumo de ração diário dos suínos machos não castrados não foi influenciado $(\mathrm{P}>0,05)$ pela concentração de lisina digestível da dieta (Tabela 2). Da mesma forma, CASTAGNA et al. (1999), avaliando lisina na dieta de suínos machos não castrados, GASPAROTTO et al. (2001) e ABREU et al. (2007), em estudo de exigência de lisina para suínos machos castrados, e FONTES et al. (2000) e FORTES (2009), na avaliação de exigência de lisina para leitoas, também não verificaram efeito da concentração de lisina na dieta sobre o consumo de ração para a fase de crescimento.

Por outro lado, constatou-se que os suínos machos castrados apresentaram consumo diário de ração superior $(\mathrm{P}<0,05)$ aos machos não castrados alimentados com as dietas contendo 1,00; 1,10 e 1,20\% de lisina digestível, mas semelhante $(\mathrm{P}>0,05)$ aos alimentados com a dieta contendo 0,90\% de lisina digestível. Essa resposta pode ser um indicativo de que os suínos não castrados ajustaram o consumo em função das dietas experimentais, ou seja, aumentaram gradativamente a ingestão de alimento em função da redução da concentração de aminoácidos da dieta. Entretanto, OWEN et al. (1994), avaliando dietas contendo ampla variação da concentração de lisina $(0,50 ; 1,10$ e $1,60 \%)$, fornecidas em sistema de livre escolha, verificaram que os suínos não foram capazes de regular o consumo de ração de acordo com a concentração de lisina na dieta. Além disso, EDMONDS \& BAKER (1987) concluíram que o excesso de lisina na dieta não influencia a ingestão de ração pelos suínos.

A concentração de lisina digestível na dieta influenciou $(\mathrm{P}<0,05)$ o consumo de lisina diário (CLD), que aumentou de forma linear de acordo com a equação: CLD $=14,073+1,3901$ Lisina digestível, $\mathrm{r}^{2}=0,98$. Como não se observou variação na ingestão voluntária de alimento entre os tratamentos, o aumento do consumo de lisina diário está diretamente relacionado à concentração de lisina digestível na dieta e, portanto, é um resultado esperado.

Houve aumento linear $(\mathrm{P}<0,05)$ do consumo de lisina por quilograma de ganho em peso (CLGPD) dos suínos machos não castrados em função do aumento da concentração de lisina digestível na dieta, conforme equação: CLGPD g kg${ }^{-1}=19,107+1,1249$ Lisina digestível, $\mathrm{r}^{2}=0,92$. Além disso, foi constatado maior $(\mathrm{P}<0,05)$ consumo de lisina por quilograma de ganho 
em peso dos machos castrados (25,61 $\left.\mathrm{g} \mathrm{kg}^{-1}\right)$ em relação aos machos não castrados. Esse resultado pode ser justificado pela baixa eficiência de utilização da fração proteica da dieta para deposição de proteína na carcaça que os machos castrados apresentam quando comparados aos machos não castrados.

Por sua vez, o nível de lisina digestível com o qual se obteve maior ganho em peso para os suínos machos não castrados resultou no consumo de 23,59g de lisina por quilograma de ganho, resultado que foi superior ao valor de $20,06 \mathrm{~g} \mathrm{~kg}^{-1}$, preconizado pelas tabelas brasileiras de exigências nutricionais (ROSTAGNO et al., 2005), para suínos machos castrados de alto potencial genético dos 30 aos $60 \mathrm{~kg}$.

Foi observado efeito $(\mathrm{P}<0,05)$ da concentração de lisina digestível na dieta sobre a conversão alimentar (CA) dos suínos machos não castrados (Tabela 2), que melhorou de forma linear de acordo com a equação: CA=3,25578-1,02925 Lisina digestível, $\mathrm{r}^{2}=0,91$.

$\mathrm{O}$ aumento do ganho em peso associado à melhora da eficiência alimentar dos machos não castrados alimentados com a dieta contendo maior concentração de lisina digestível seria uma evidência de que pode ter ocorrido modificação na composição do ganho de peso com provável aumento da deposição diária de proteína em detrimento da deposição diária de gordura. Essa hipótese é confirmada em estudo realizado por LATORRE et al. (2008), em que constataram correlação alta e positiva entre ganho diário em proteína e conversão alimentar, indicando que suínos com alta taxa de ganho diário de tecido proteico apresentam melhor eficiência alimentar.

Além disso, essa proposição também pode ser justificada pelo fato de que a deposição de tecido proteico agrega mais moléculas de água $(1: 3,4)$ em relação à deposição de lipídios na carcaça (HALAS et al., 2010), resultando na melhora tanto do ganho em peso, quanto da eficiência alimentar.

Verificou-se que os machos não castrados consumindo dietas contendo 1,00; 1,10 e 1,20\% apresentaram melhor $(\mathrm{P}<0,05)$ conversão alimentar em relação aos castrados. Esse resultado evidencia a melhor eficiência de utilização dos nutrientes das dietas pelos suínos machos não castrados quando comparados aos castrados para ganho em peso (XUE et al., 1997).

No grupo de machos não castrados, os que foram alimentados com a dieta contendo 1,20\% de lisina apresentaram 13,6\% de melhora na conversão alimentar, $9,7 \%$ no ganho em peso diário e aumento de $4,6 \%$ do peso final (PF) em relação aos machos não castrados alimentados com a dieta contendo 0,90\% de lisina digestível. Dessa forma, o aumento linear do ganho em peso diário observado nos machos não castrados proporcionou animais mais pesados ao final do experimento $(\mathrm{P}<0,05)$, segundo a equação: $\mathrm{PF}=49,77488+8,49$ Lisina digestível, $\mathrm{r}^{2}=0,98$.

Por sua vez, apenas os machos não castrados consumindo a dieta contendo $1,20 \%$ de lisina digestível apresentaram peso final $(\mathrm{P}<0,05)$ superior aos castrados, resultado que está coerente com a resposta obtida para o ganho em peso neste estudo.

Em razão da variação linear observada neste estudo, não foi possível estabelecer as exigências nutricionais de lisina dos suínos. Porém, os resultados indicaram que suínos machos não castrados, de alto potencial genético, exigem no mínimo 1,20\% de lisina digestível na dieta.

As tabelas brasileiras de exigências nutricionais (ROSTAGNO et al., 2005) não apresentam informações relacionadas às exigências para os suínos machos não castrados. Contudo, os níveis preconizados pelas tabelas para suínos machos castrados e fêmeas de alto potencial genético correspondem, respectivamente, a 1,00 e 1,10\%, sendo inferiores ao valor obtido para a máxima resposta de desempenho dos suínos neste estudo. Esse resultado confirma os relatos de WILLIAMS et al. (1984) e YEN et al. (1986) de que suínos machos não castrados apresentam exigência de lisina digestível superior aos machos castrados e às fêmeas.

\section{CONCLUSÃO}

Suínos machos não castrados de alto potencial genético em fase de crescimento exigem no mínimo 1,20\% de lisina digestível na dieta para máximo desempenho.

\section{AGRADECIMENTOS}

Ao Conselho Nacional para o Desenvolvimento Científico e Tecnológico (CNPq), pela bolsa de Pós-doutorado concedida a Charles Kiefer e aos proprietários da Suinocultura Rancho Alegre, Arão Antônio Moraes e Jussara Moraes, pelo apoio na realização deste estudo.

\section{REFERÊNCIAS}

ABREU, M.L.T. et al. Níveis de lisina digestível em rações, utilizando-se o conceito de proteína ideal, para suínos machos castrados de alto potencial genético, dos 30 aos 60kg. Revista Brasileira de Zootecnia, v.36, p.62-67, 2007. Disponível em: <http://www.scielo.br/pdf/rbz/v36n1/a08v36n1.pdf>. Acesso em: 12 nov. 2009. doi: 10.1590/S151635982007000100008 .

CASTAGNA, C.D. et al. Níveis de aminoácidos na dieta de suínos machos inteiros dos 25 aos 70kg. Ciência Rural, v.29, 
p.117-122, 1999. Disponível em: <http://www.scielo.br/pdf/ cr/v29n1/a21v29n1.pdf >. Acesso em: 10 ago. 2009. doi: 10.1590/S0103-84781999000100021.

DONZELE, J.L. et al. Níveis de lisina para suínos machos inteiros dos 30 aos $60 \mathrm{~kg}$ de peso vivo. Revista Brasileira de Zootecnia, v.23, p.974-982, 1994.

EDMONDS, M.S.; BAKER, D.H. Aminoacids excesses for young pigs: Effects of excess methionine, tryptophan, threonine or leucine. Journal of Animal Science, v.64, p.1664-1671, 1987. Disponível em: <http://jas.fass.org/cgi/reprint/64/6/ 1664>. Acesso em: 10 fev. 2010.

FÁVERO, J.A. Abate de suínos machos inteiros - visão brasileira. In: CONFERÊNCIA INTERNACIONAL VIRTUAL SOBRE QUALIDADE DE CARNE SUÍNA, 2001, Concórdia. Anais... Santa Catarina: EMBRAPA, 2001. p.212-220.

FONTES, D.O. et al. Níveis de lisina para leitoas selecionadas geneticamente para deposição de carne magra, dos 30 aos $60 \mathrm{~kg}$, mantendo constante a relação entre lisina e metionina + cistina, treonina, triptofano, isoleucina e valina. Revista Brasileira de Zootecnia, v.29, p.776-783, 2000. Disponível em: <http:/ /www.scielo.br/pdf/rbz/v29n3/5823.pdf>. Acesso em: 10 ago. 2009. doi: 10.1590/S1516-35982000000300020.

FORTES, E.I. Níveis de lisina digestível e planos de nutrição para suínos machos castrados de duas linhagens genéticas. 2009. 46f. Dissertação (Mestrado em Zootecnia) - Curso de Pós-graduação em Zootecnia, Universidade Federal de Viçosa, MG.

FULLER, M.F. et al. The optimum dietary amino acid pattern for growing pigs. British Journal of Nutrition, v.62, p.7789, 1989. Disponível em: <http://journals.cambridge.org/action/ display Fulltext ?type $=1 \& \mathrm{fid}=934840 \&$ jid $=$ \& volume I d $=\&$ is su e I d $=01 \&$ a i d $=934832$ \&bodyId=\&membershipNumber=\&societyETOCSession=> . Acesso em: 10 ago. 2009. doi: 10.1079/BJN19890028.

GASPAROTTO, L.F. et al. Exigência de lisina, com base no conceito de proteína ideal, para suínos machos castrados de dois grupos genéticos, na fase de crescimento. Revista Brasileira de Zootecnia, v.30, p.1742-1749, 2001 Disponível em: <http://www.scielo.br/pdf/rbz/v30n6/7303.pdf>. Acesso em: 10 ago. 2009. doi: 10.1590/S151635982001000700012 .

GRANDHI, R.R.; NYACHOTI, C.M. Effect of true ileal digestible dietary methionine to lysine ratios on growth performance and carcass merit of boars, gilts and barrows selected for low backfat. Canadian Journal of Animal Science, v.82, p.399-407, 2002. Disponível em: <http://ginkgo.cisti.nrc.ca/RPAS/ rpv?hm=HInit\&journal=cjas\&volume=82\&afpf $=$ A01-015.pdf $>$. Acesso em: 10 ago. 2009.

HALAS, V. et al. Efficiency of fat deposition from non-starch polysaccharides, starch and unsaturated fat in pigs. British Journal of Nutrition, v.103, p.123-133. 2010. Disponível em: $<$ h t t : / / journals.cambridge.org/action/ displayAbstract?fromPage $=$ online $\&$ aid $=6889092>$. Acesso em: 05 maio, 2010. doi: 10.1017/S0007114509991449.

LATORRE, M.A. et al. The relationship within and between production performance and meat quality characteristics in pigs form three different genetic lines. Livestock Science, v.115, p.258-267, 2008.

OWEN, K.Q. et al. Self-selection of diets and lysine requirements of growing-finishing swine. Journal of Animal Science, v.72, p.554-564, 1994. Disponível em: <http://jas.fass.org/ cgi/reprint/72/3/554>. Acesso em: 10 ago. 2009.

ROSTAGNO, H.S. et al. Tabelas brasileiras para aves e suínos: composição de alimentos e exigências nutricionais. 2.ed. Viçosa: UFV, 2005. 186p.

SAMPAIO, C.A.P. et al. Avaliação do ambiente térmico em instalações para crescimento e terminação de suínos utilizando os índices de conforto térmico nas condições tropicais. Ciência Rural, v.34, p.785-790, 2004. Disponível em: <http:// www.scielo.br/pdf/cr/v34n3/a20v34n3.pdf>. Acesso em: 18 mar. 2010. doi: 10.1590/S0103-84782004000300020.

SAS - STATISTICAL ANALYSES SYSTEM. SAS/STAT software, version 8.02. Cary, 2001. 1686p.

XUE, J.L. et al. Performance, carcass and meat quality advantages of boars over barrows: a literature review. Swine Health Production, v.1, p.21-28, 1997. Disponível em: $<$ https://www.aasv.org/shap/issues/v5n1/v5n1p21.html>. Acesso em: 10 ago. 2009.

WILLIAMS, W.D. et al. The lysine requirement of the growing boar versus barrow. Journal of Animal Science, v.58, p.657665, 1984. Disponível em: <http://jas.fass.org/cgi/reprint/58/ 3/657>. Acesso em: 10 ago. 2009.

YEN, H.T. et al. Amino acid requirements of growing pigs. 7. The response of pigs from 25 to $55 \mathrm{~kg}$ live weight to dietary ideal protein. Animal Production, v.43, p.141-154, 1986. 